\title{
Examination of Microcystin Neurotoxicity Using Central and Peripheral Human Neurons
}

\author{
Stefanie Klima1,2, Ilinca Suciu1,5, Lisa Hoelting1, Simon Gutbier1, Tanja Waldmann', Daniel Dietrich2,3 \\ and Marcel Leist 1,4 \\ ${ }^{1}$ In vitro Toxicology and Biomedicine, Dept inaugurated by the Doerenkamp-Zbinden Foundation, University of Konstanz, Konstanz, Germany; \\ ${ }^{2}$ Cooperative doctorate college InViTe, University of Konstanz, Konstanz, Germany; ${ }^{3}$ Human and Environmental Toxicology, University of Konstanz, \\ Konstanz, Germany; ${ }^{4}$ CAAT-Europe, University of Konstanz, Konstanz, Germany; ${ }^{5}$ Konstanz Research School Chemical Biology (KoRS-CB), \\ University of Konstanz, Konstanz, Germany
}

\begin{abstract}
Microcystins (MC) are a group of cyanobacterial toxins that comprises MC-LF and other cyclic heptapeptides, best known as potent hepatotoxicants. Cell culture and epidemiological studies suggest that $M C$ might also affect the nervous system when there is systemic exposure, e.g., via drinking water or food. We asked whether in vitro studies with human neurons could provide estimates on the neurotoxicity hazard of MC-LF. First, we used LUHMES neurons, a well-established test system for neurotoxicants and neuropathological processes. These central nervous system cells express OATP1A2, a presumed carrier of MC-LF, and we observed selective neurite toxicity in the $\mu M$ range (EC20 $=3.3 \mu \mathrm{M} \approx 3.3 \mu \mathrm{g} / \mathrm{mL}$ ). Transcriptome changes pointed towards attenuated cell maintenance and biosynthetic processes. Prolonged exposure for up to four days did not increase toxicity. As a second model, we used human dorsal root ganglia-like neurons. These peripheral nervous system cells represent parts of the nervous system not protected by the blood-brain barrier in humans. Toxicity was observed in a similar concentration range $(E C 20=7.4 \mu M)$. We conclude that MC-LF poses a potential neurotoxic hazard in humans. The adverse effect concentrations observed here were orders of magnitude higher than those presumed to be encountered after normal nutritional or environmental exposure. However, the low $\mu M$ concentrations found to be toxic are close to levels that may be reached after very excessive algae supplement intake.
\end{abstract}

\section{Introduction}

While microcystins (MCs) are widely known for their acute hepatotoxicity (Carmichael, 1992; Nishiwaki-Matsushima et al., 1992), their potentially adverse effects on other target organs, such as the nervous system, are less clear. MCs are small cyclic heptapeptides comprised of $5 \mathrm{D}$ - and $2 \mathrm{~L}$-amino acids (cyclo-D-Ala 1 -X ${ }^{2}-\mathrm{D}-\mathrm{MeAsp}{ }^{3}-Z^{4}-\mathrm{Adda}^{5}-\mathrm{D}-\mathrm{Glu}^{6}-\mathrm{Mdha}^{7}$ ). Structural variation of side-chains has been encountered in all seven positions, but the most variable amino acids ( $\mathrm{X}$ and $\mathrm{Z}$ ) are the L-amino acids in positions 2 and 4 (Botes et al., 1984; Daneshian et al., 2013). These variable L-amino acid residues are used for naming of the MC congeners, of which more than 248 different congeners are known to date (Altaner et al., 2019; Spoof and Catherine, 2016). For example, in MC-LF these amino acids are L-leucine (L) and L-phenylalanine (F). A number of ubiquitously present cyanobacteria genera, e.g., Microcystis, Planktothrix,
Anabaena and Dolichospermum, have been shown to produce MC (Svirčev et al., 2019).

The main exposure route for humans is drinking water, albeit excessive exposure can occur when cyanobacterial supplements are consumed voluntarily (Heussner et al., 2012; Dietrich and Hoeger, 2005). The World Health Organization (WHO) suggested a safe value of $1 \mu \mathrm{g} / \mathrm{L}(1 \mathrm{nM})$ for MC-LR in their guidance on cyanobacteria in drinking water ${ }^{1}$. Based on the latter, the tolerable daily intake (TDI) for a human was calculated to be $0.04 \mu \mathrm{g} \mathrm{MC}-\mathrm{LR}_{\text {equivalents }} / \mathrm{kg}$ body weight/day $(\approx 40 \mathrm{pmol} / \mathrm{kg}$ body weight/day). In addition to the well-established hepatotoxicity, renal and neurotoxicity also have been reported based on in vivo and in vitro experiments in rodents, fish and birds (Fischer and Dietrich, 2000; Feurstein et al., 2009, 2011; Hu et al., 2016; Herrera et al., 2018; Hinojosa et al., 2019).

There have been several reported human exposures to MCs with an adverse outcome. In Caruaru, Brazil (Jochimsen et al., 1998;
Received March 18, 2020; Accepted June 9, 2020;

Epub June 23, 2020; (c) The Authors, 2020.

ALTEX 38(1), 073-081. doi:10.14573/altex.2003182

Correspondence: Marcel Leist, PhD

In vitro Toxicology and Biomedicine

Dept inaugurated by the Doerenkamp-Zbinden Foundation

University of Konstanz

Universitaetsstr. 10, 78457 Konstanz, Germany

(marcel.leist@uni-konstanz.de)
This is an Open Access article distributed under the terms of the Creative Commons Attribution 4.0 International license (http://creativecommons.org/licenses/by/4.0/) which permits unrestricted use, distribution and reproduction in any medium, provided the original work is appropriately cited. 
Pouria et al., 1998), patients at a hemodialysis clinic were accidentally exposed via dialysis water with an estimated MC concentration of $19.5 \mu \mathrm{g} / \mathrm{L}(20 \mathrm{nM})$ (Azevedo et al., 2002). The symptoms reported in the patients ranged from early visual disturbances to muscle weakness and nausea. Of the 126-131 patients, 100 developed acute liver toxicity and between 52 and 60 of them died within 10 months (Azevedo et al., 2002; Pouria et al., 1998).

At lake Chaohu, China, fishermen were chronically exposed to $\mathrm{MCs}$ via drinking water and food. Concentrations of $\mathrm{MC}$ were $3.28 \mu \mathrm{g} / \mathrm{L}$, which corresponds to $3.3 \mathrm{nM} \mathrm{MC}$-LR equivalents, in drinking water. The muscle of contaminated aquatic animals showed MC concentrations of $43 \mathrm{ng} / \mathrm{g}$ dry weight (DW) (43 pmol MC-LR equivalent $/ g$ DW), which led to blood concentrations in fishermen ranging from 0.045 to $1.832 \mathrm{ng} / \mathrm{mL}(0.045$ to $1.84 \mathrm{pM})$ (Chen et al., 2009). Blood samples showed increased levels of liver enzymes such as alanine aminotransferase.

In the Chinese Three Gorges Reservoir Region, more than 1000 children were chronically exposed to MC. They showed elevated levels of alanine aminotransferase compared to non-exposed children ( $\mathrm{Li}$ et al., 2011). The average drinking water concentration of $\mathrm{MC}$ was $2.6 \mu \mathrm{g} / \mathrm{L}(2.6 \mathrm{nM})$, the mean concentration in fish was $0.22 \mu \mathrm{g} / \mathrm{g} \mathrm{DW}(221.1 \mathrm{nmol} / \mathrm{g} \mathrm{DW})$.

MCs need to be actively transported into cells by organic anion transporting polypeptides (OATPs). Cells of the blood-brain barrier as well as neurons express OATP1A2 (Hagenbuch and Meier, 2003; Bronger et al., 2005). This suggests that MCs can cross the blood-brain barrier, as OATP1A2 has been shown to transport MC-LR (Fischer et al., 2005). The best-documented mode of action of $\mathrm{MC}$ in mammalian cells (hepatocytes) is the inhibition of serine/ threonine-specific protein phosphatase 1, 2A and 5 (MacKintosh et al., 1990; Buratti et al., 2017; Valério et al., 2016; Chen and Xie, 2016; Altaner et al., 2020). This results in hyperphosphorylation of several protein kinase targets, which eventually leads to widespread dysregulation of cellular processes (Yoshizawa et al., 1990; MacKintosh et al., 1990; Hinojosa et al., 2019).

As epidemiological and animal data from rodents, fish and birds suggest that MCs may induce neurotoxicity in addition to hepatotoxicity, we explored MC toxicity to human neurons. We used LUHMES cells as representatives of central human neurons (Lotharius et al., 2005; Scholz et al., 2011). These cells have a normal karyotype (Gutbier et al., 2018) and typical neuronal structure and electrophysiology (Scholz et al., 2011). They have been widely used as alternatives to animal testing and in neuropathology studies (Witt et al., 2017; Lohren et al., 2015; Delp et al., 2019, 2018; Singh et al., 2018; Scholz et al., 2018; Tong et al., 2018; Höllerhage et al., 2017; Devos et al., 2014; Skirzewski et al., 2018). As a second, complementary test system, we used human peripheral neurons. These were generated from pluripotent stem cells (Hoelting et al., 2016) and have been established as a screening system for peripheral neurotoxicants (Delp et al.,
2018). These two models were used in an in vitro approach to identify neurotoxic MC concentrations in order to compare them to serum concentrations reported in humans after exposure.

\section{Materials and methods}

\section{Materials}

Cisplatin, valinomycin, tubacin, microcystin-LF, microcystinLR, PLO, fibronectin, glutamine, tetracycline, cAMP, apotransferrin, glucose, insulin, putrescine, selenium, progesterone and calcein-AM were purchased from Sigma, USA. AdvDMEM/ F12, knockout serum replacement, DMEM/F12, N2 supplement, Glutamax, NEAA, $\beta$-mercaptoethanol, Triton-X-100, PBS, H-33342, fetal bovine serum (FBS), Trizol, Flou-4 Direct ${ }^{\mathrm{TM}}$ Calcium Assay Kit were purchased from ThermoFisher Scientific, USA. FGF2, GDNF, noggin, BDNF and NGF were purchased from R\&D systems, USA. Dorsomorphin, SB-431642 and SU5402 were purchased from Torcis, UK. Chir99021 was purchased from Axon Medchem, USA; DAPT was purchased from Merck Millipore, USA; Matrigel was purchased from Corning, USA; iScript and SsoFast ${ }^{\mathrm{TM}}$ EvaGreen ${ }^{\circledR}$ Supermix were purchased from BioRad, USA. Pacific ciguatoxin (pCTX) isolated from a moray eel, was provided by the laboratory of Richard Lewis, University of Queensland, Brisbane, Australia. Chemical structures were drawn with ChemDraw (Version 16.0) from PerkinElmer.

\section{LUHMES culture}

LUHMES were cultured as described earlier (Krug et al., 2013; Lotharius et al., 2005; Scholz et al., 2011). Briefly, cells were cultured on PLO/fibronectin ( $50 \mu \mathrm{g} / \mathrm{mL}$ poly-L-ornithine (PLO) and $1 \mu \mathrm{g} / \mathrm{mL}$ fibronectin) coated flasks and plates. Cells were maintained in proliferation medium (AdvDMEM/F12 supplemented with $2 \mathrm{mM}$ glutamine, 1x N2 supplement and $40 \mathrm{ng} / \mathrm{mL}$ fibroblast growth factor-2 (FGF2)). Differentiation was initiated by seeding cells at a density of 100,000 cells $/ \mathrm{cm}^{2}$ in proliferation medium and changing the medium after $24 \mathrm{~h}$ to differentiation medium (AdvDMEM/F12 supplemented with $2 \mathrm{mM}$ glutamine, 1x N2 supplement, $2.25 \mu \mathrm{M}$ tetracycline, $1 \mathrm{mM}$ dibutyryl 3',5'-cyclic adenosine monophosphate (cAMP) and $2 \mathrm{ng} / \mathrm{mL}$ recombinant human glial cell derived neurotrophic factor (GDNF)). Medium change was performed every $48 \mathrm{~h}$ after the differentiation was started.

\section{Peripheral neurons}

The stem cell line (WA09 line) was obtained from WiCell (Madison, WI, USA). The pluripotent stem cells were differentiated on Matrigel-coated plates into immature dorsal root ganglia-like neurons exactly according to the protocol of Hoelting et al. (2016).

\footnotetext{
1 https://www.who.int/water_sanitation_health/dwq/GDWQ2004web.pdf?bcsi_
} 
Briefly, differentiation was started on day of differentiation (DoD) 0 ' by adding neural differentiation medium (KSR-S; knockout DMEM with $15 \%$ serum replacement, 1x Glutamax, 1x non-essential amino acids, and $50 \mu \mathrm{M} \beta$-mercaptoethanol) and six small molecule pathway inhibitors $(35 \mathrm{ng} / \mathrm{mL}$ noggin, $600 \mathrm{nM}$ dorsomorphin, $10 \mu \mathrm{M}$ SB-431642, 1.5 $\mu \mathrm{M}$ CHIR99021, $1.5 \mu \mathrm{M}$ SU5402, and $5 \mu \mathrm{M}$ DAPT). Starting from DoD4', medium was gradually replaced by N2-S medium (DMEM/F12 with $2 \mathrm{mM}$ Glutamax, $0.1 \mathrm{mg} / \mathrm{mL}$ apotransferrin, $1.55 \mathrm{mg} / \mathrm{mL}$ glucose, $25 \mathrm{mg} / \mathrm{mL}$ insulin, $100 \mathrm{mM}$ putrescine, $30 \mathrm{nM}$ selenium, and $20 \mathrm{nM}$ progesterone). After eight days of differentiation, the neuronal precursors were cryopreserved. After thawing, cells were seeded at a density of 100,000 cells $/ \mathrm{cm}^{2}$ in $25 \% \mathrm{KSR}-\mathrm{S}$ and $75 \% \mathrm{~N} 2-\mathrm{S}$ supplemented with 1.5 $\mu \mathrm{M}$ CHIR99021, $1.5 \mu \mathrm{M}$ SU5402, and $5 \mu \mathrm{M}$ DAPT. On DoD1 and DoD2, 50\% of the medium was changed. From DoD3 on, cells received N2-S medium supplemented with $10 \mathrm{ng} / \mathrm{mL}$ $\mathrm{BNDF}, 10 \mathrm{ng} / \mathrm{mL}$ GNDF, and $25 \mathrm{ng} / \mathrm{mL}$ NGF for further differentiation and maturation, with medium changes every other day.

Since Matrigel is chemically rather undefined and from an animal source, we tried to replace it with vitronectin or laminin-521. However, none of these coatings allowed differentiation comparable to Matrigel.

\section{$\mathrm{Ca}^{2+}$ signaling}

Peripheral neurons were seeded at a density of $100,000 \mathrm{cells} / \mathrm{cm}^{2}$ and cultured according to Hoelting et al. (2016). After 23 days of differentiation, the cells were loaded with Fluo4 AM-Calcium Assay Kit and Hoechst-33342 (H-33342) for $20 \mathrm{~min}$ at $37^{\circ} \mathrm{C}$. Changes in the free intracellular $\mathrm{Ca}^{2+}$ concentration were monitored with a VTI HCS microscope (Cellomics, USA) containing an incubation chamber providing an atmosphere with $5 \% \mathrm{CO}_{2}$ at $37^{\circ} \mathrm{C}$. Substances (Hank's balanced salt solution, $0.3 \%$ dimethylsulfoxide (DMSO), $2.5 \mu \mathrm{M}$ MC-LF, $30 \mathrm{mM} \mathrm{KCl,} 15 \mathrm{nM}$ pCTX) were administered by an automated pipettor $10 \mathrm{~s}$ after the first image was taken. Images were taken as fast as possible for $45 \mathrm{~s}$ (approx. one image/second) and exported as .avi files. The files were analyzed in CaFFEE software (Karreman et al., 2020).

\section{Viability testing}

LUHMES and peripheral neurons were seeded at a density of 100,000 cells $/ \mathrm{cm}^{2}$, cultured, and treated as indicated in the respective figure. One hour prior to analysis, cells were stained with staining mix ( $1 \mu \mathrm{g} / \mathrm{mL} \mathrm{H}-33342$ and $1 \mu \mathrm{M}$ calcein-AM), incubated for one hour at $37^{\circ} \mathrm{C}$, and image acquisition was performed automatically with ArrayScan VTI HCS microscope (Cellomics, USA). Analysis of the pictures was performed as described earlier (Stiegler et al., 2011). Briefly, the neuronal area was identified by calcein stain, and the somatic area was subtracted, which resulted in definition of neurite area. The viability was obtained from the same images. Cells with a double stain for H-33342 and calcein were counted as alive, whereas cells only positive for $\mathrm{H}-33342$ were classified as dead.

\section{Immunofluorescence and microscopy}

Cells were grown on PLO/fibronectin or Matrigel-coated 96well plates and fixed with 4\% paraformaldehyde on day 6 (d6)
(LUHMES) or DoD7 (peripheral neurons). Following permeabilization in $0.3 \%$ Triton X-100, they were blocked for $1 \mathrm{~h}$ in PBS containing $5 \%$ fetal bovine serum and $0.1 \%$ Triton X-100. Primary antibodies (Tuj1 (BioLegend Cat. No. 801202) 1:1000, OATP1A2 (Sigma-Aldrich Cat. No. SAB4502814) 1:100, Peripherin (Santa Cruz Cat. No. sc-7604) 1:200) were added for $1 \mathrm{~h}$ at room temperature. After washing, secondary antibodies and H-33342 were incubated for $30 \mathrm{~min}$. Images were taken at a Zeiss Axio Observer with ZEN 2 pro blue edition software and further processed with ImageJ (Version 1.52p).

FBS is included in many blocking buffers in immunofluorescence staining protocols. We tried to replace it with milk powder, but the antibodies applied in this study did not give satisfying fluorescence signals in milk powder.

\section{$R N A$ extraction, $c D N A$ synthesis and real-time $q P C R$}

Total RNA was extracted using TRIzol, according to the manufacturer's protocol. Total RNA $(1 \mu \mathrm{g})$ was reverse transcribed with iScript. Quantification of cDNA was performed using the SsoFast ${ }^{\mathrm{TM}}$ EvaGreen ${ }^{\circledR}$ Supermix. The threshold cycle $\left(\mathrm{C}_{\mathrm{T}}\right)$ was determined for each sample using the CFX data analysis software (Bio-Rad, USA). RPL13A was used as reference gene (forward: GGTATGCTGCCCCACAAAACC reverse: CTGTCACTGCCTGGTACTTCCA); mRNA levels of OATP1A2 (forward: TCCTGTGTGTGGAAACAATG reverse: AGCATCAAGGAACAGTCAGG) and OATP3A1 (forward: CTGGGCTCTTTCTGTACCAA reverse: GTGGAAACCCAAACATCAAG) were compared to the reference gene using the $\Delta \Delta$ method (Livak and Schmittgen, 2001).

\section{Transcriptome data generation and analysis}

For the sample preparation, the medium was removed from each well, and cells were immediately lysed in $25 \mu \mathrm{L}$ of $1 \mathrm{x}$ Biospyder lysis buffer. Samples were stored at $-80^{\circ} \mathrm{C}$ until shipment to Bioclavis (BioSpyder Tech.) on dry ice. TempO-Seq, a targeted RNA-sequencing method developed by BioSpyder Technologies, Inc., described in detail by House et al. (2017) was used for the transcriptomics data.

The R package DESeq2 (v1.24.0) was employed for transcriptomics data analysis (Love et al., 2014). The DESeq2 object was constructed from raw counts, and its size factors were coerced to total sample counts per million (CPM). Analysis of differential gene expression in the treatment group (against the DMSO control group) was done with the Wald test. The threshold of Benjamini-Hochberg adjusted p-values $\leq 0.05$ had to be satisfied in order for a gene to be considered significantly deregulated. Overrepresentation analysis was based on Fisher's F-test as implemented in G-profiler software (Raudvere et al., 2019). Principal component analysis (PCA) was generated using the online tool ClustVis (Metsalu and Vilo, 2015).

\section{Statistics}

Experiments were performed at least on two (usually on three) cell preparations ("N"), with several ( $\geq 3$ ) technical replicates for each cell batch ("n"). For statistical analysis, GraphPad Prism 5 software (Version 5.03) was used. Data were evaluated by 

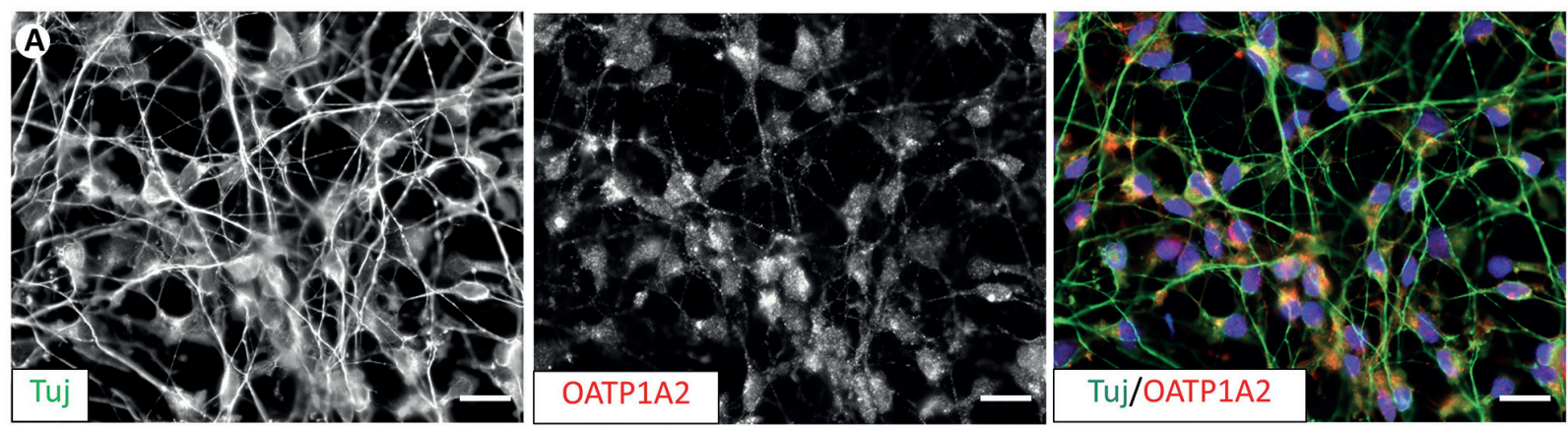

B

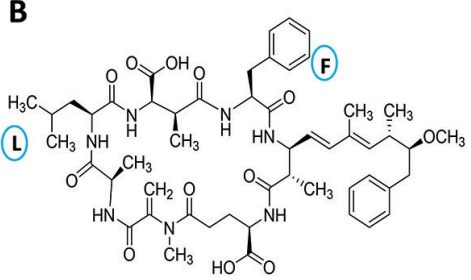

MC-LF

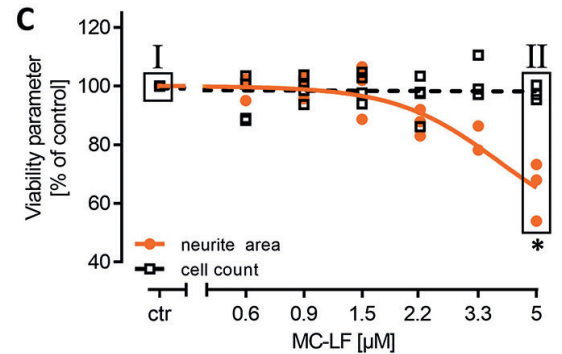

D

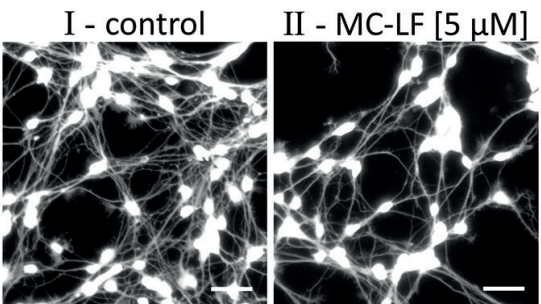

\section{Fig. 1: Effect of MC-LF on LUHMES neurons}

(A) LUHMES cells were differentiated on coverslips and fixed after six days. Double-immunofluorescence images were obtained for neurite structures (using an antibody against $\beta$-III-tubulin, Tuj) and for OATP1A2. The individual channels are shown in b/w for maximum clarity, the composite image is shown with neurites in green and OATP1A2 in red. Scale bar is $20 \mu \mathrm{m}$. $(\mathrm{N}=2, \mathrm{n}=5)(\mathrm{B}) \mathrm{Chemical}$ structure of MC-LF. (C) Effect of MC-LF on neurite area (orange) and cell count (black) after $48 \mathrm{~h}$ treatment from d4 until d6. Data points are from three separate experiments, each with three technical replicates ${ }^{*}, p<0.05$. (D) Exemplary pictures of calcein-stained cells treated with $5 \mu \mathrm{M}$ MC-LF (II) or solvent (I), as described in C. Scale bar is $50 \mu \mathrm{m}$.

ANOVA with post-hoc testing (Dunnett's) or by t-test (two groups) as appropriate. P-values $<0.05$ were regarded as statistically significant. For curve fitting, a four-parameter fit with top constrains set to $100 \%$ was used in GraphPad Prism 5 software (Version 5.03).

\section{Results and discussion}

\subsection{Neurotoxicity of MC-LF, assessed on LUHMES neurons}

LUHMES neurons differentiated for 4-6 days are not only fully post-mitotic (Scholz et al., 2011) but show many features of central nervous system cells (Tong et al., 2018; Gutbier et al., 2018; Matelski et al., 2020; Weng et al., 2012, 2014). The cells were confirmed to be positive for OATP1A2, a transporter that accepts microcystins (MCs) as substrate (Fig. 1A) (Fischer et al., 2005; Chen and Xie, 2016). When LUHMES cells were exposed to MC-LF (Fig. 1B) for $48 \mathrm{~h}$, we observed specific neurite degeneration at concentrations above about $2 \mu \mathrm{M}$ (Fig. 1C,D). The number of viable cells (= cell bodies) was not affected at concentrations as high as $5 \mu \mathrm{M}$ (Fig. 1C). Follow-up experiments showed that $24 \mathrm{~h}$ exposure was not sufficient to trigger neurite damage (Fig. $\mathrm{S} 1 \mathrm{~A}-\mathrm{C}^{2}$ ). Exposure for $24 \mathrm{~h}$ followed by a $24 \mathrm{~h}$ washout period led to the same toxicity as $48 \mathrm{~h}$ continuous exposure (Fig. S1D ${ }^{2}$ ). This suggests that toxic effects were all triggered during the first $24 \mathrm{~h}$, but manifestation of toxicity (neurite breakdown) took a further day to develop. We tested whether even longer times would allow for more potent toxicant effects. However, exposure for $48 \mathrm{~h}$ followed by a 48-h washout (4 days in total) did not lead to more potent effects of MC-LF (Fig. S1E ${ }^{2}$ ). To further investigate effect specificity, we also investigated MC-LR (Fig. S1F ${ }^{2}$ ), known to be a less potent toxicant (Feurstein et al., 2011). Indeed, no toxicity was observed here at concentrations up to $5 \mu \mathrm{M}$ (Fig. $\mathrm{S}_{1 \mathrm{G}^{2}}$ ). To test for potentially more subtle effects of $\mathrm{MC}$ on neurons, several other endpoints were considered. Tau phosphorylation and activation of MAP kinases (ERK) were examined by Western blotting, but no changes were observed at $\leq 5 \mu \mathrm{M}$ MC-LF (data not shown). Based on this series of experiments, we conclude that MC-LF can trigger neurotoxicity at high concen-

2 doi:10.14573/altex.2003182s1 
A

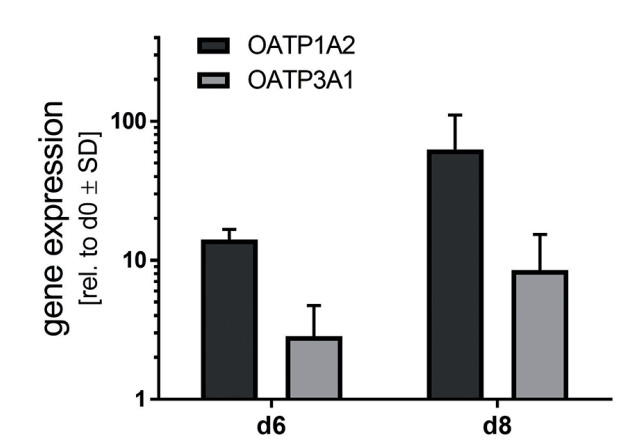

C

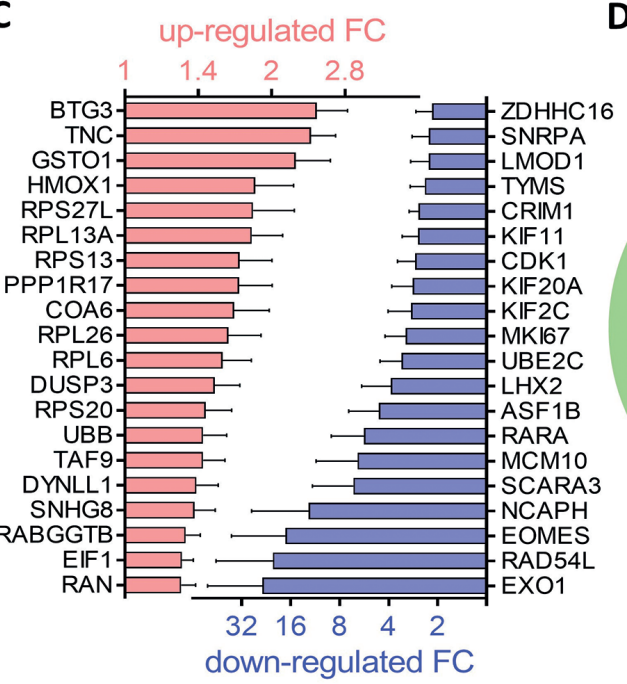

B

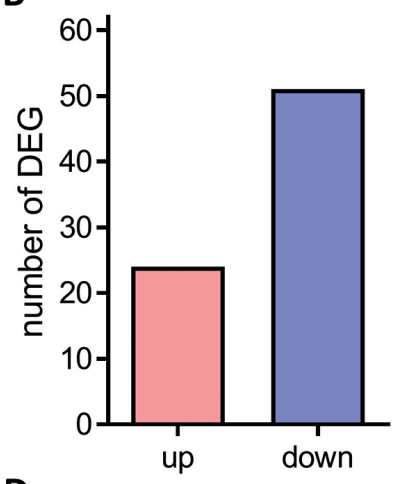

D

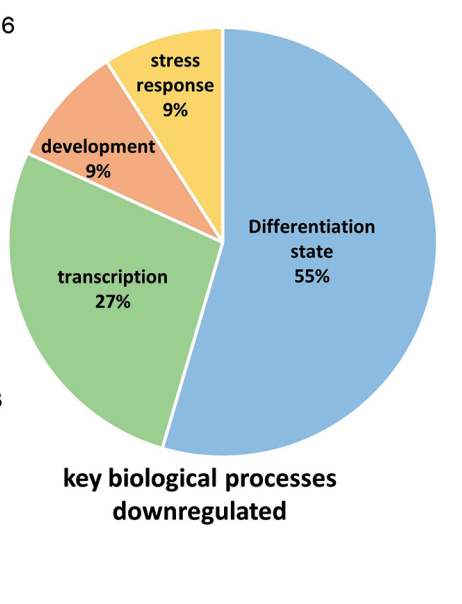

Fig. 2: Transcriptome analysis of MC-LF treated LUHMES

(A) OATP1A2 (black) and OATP3A1 (grey) expression levels of LUHMES on $\mathrm{d} 6$ and d8 relative to d0 determined with RT-qPCR. $(\mathrm{N}=2, \mathrm{n}=3)(\mathrm{B})$ Samples were obtained at d6 from untreated LUHMES and LUHMES treated with $5 \mu \mathrm{M} \mathrm{MC}$-LF for $48 \mathrm{~h}$ from d4 until d6, and RNA expression profiles were obtained $(N=4)$. Number of differentially expressed genes (DEG) is shown for upregulations (red) and downregulations (blue) with an adjusted $p$-value $\leq 0.05$. (C) Out of the DEGs in (B), the top 20 upregulated (red) and downregulated (blue) genes according to their fold change (FC) are shown. The error bars represent the standard deviation. (D) The gProfiler analysis tool was used to identify oGOs among the downregulated DEGs.

These were then assigned to four different superordinate biological processes according to Waldmann et al. (2014). trations $(>2 \mu \mathrm{M})$. Our data, based on established and sensitive endpoints of neurite toxicity, suggest that lower concentrations of MC-LF are inactive in the chosen experimental model of human neurons in the exposure scenarios employed here.

\subsection{Transcriptome disturbances triggered by MC-LF}

To broadly capture effects of MC on neurons, the transcriptional changes triggered by $48 \mathrm{~h}$ exposure to $5 \mu \mathrm{M}$ MC-LF were measured (Fig. S2A $\mathrm{A}^{2}$ ). PCA analysis clearly showed a separation between MC treatment and the control (Fig. S2B ${ }^{2}$ ). The analysis identified 75 differentially expressed genes (DEGs) (Fig. 2B). The top downregulated DEGs were mainly related to differentiation and chromatin remodeling, such as EXO1, RAD54L or $\mathrm{NCAPH}$, and thus did not indicate specific pathways (Fig. 2C). The most upregulated DEGs included predominantly ribosomal genes like RRS27L, RPL13A, RPS13 and the anti-proliferative factor BTG3. This pattern is consistent with a relatively unspecific cellular stress response. To gain a better understanding of the DEGs, we performed a gene ontology overrepresentation analysis. The upregulated DEGs resulted in more than 20 over- represented gene ontologies (oGOs) (Fig. S2C ${ }^{2}$ ). Downregulated DEGs resulted in only eleven oGOs (Fig. S2D ${ }^{2}$ ). The gene PPP1R17 (protein phosphatase 1 regulatory subunit 17) is included in the oGOs "mRNA catabolic process", "heterocycle catabolic process" (Fig. S2E²), "cellular nitrogen compound catabolic process" and "aromatic compound catabolic process". Its gene product inhibits the phosphatase activities of protein phosphatase 1 (PP1) and protein phosphatase 2A (PP2A) complexes. Inhibition of PP1 and PP2A is the best described direct mode of action of MCs (Altaner et al., 2020; MacKintosh et al., 1990; Chen and Xie, 2016; Buratti et al., 2017; Valério et al., 2016). It appears that most of the downregulated DEGs are grouped into oGOs dealing with the cell cycle (Fig. S2D ${ }^{2}$ ), but when investigated more precisely, the included genes in the respective oGOs are linked to the cell cycle only very indirectly. Exemplarily, the DEGs included in the GO "mitotic nuclear division" are mainly genes related to (neuronal) differentiation status like EMX2, SNCA, and TCF4 (Fig. S2F⿻丷木). To integrate the results of the downregulated DEGs and the GO analysis, we assigned the oGOs to key biological processes according to Waldmann et al. 


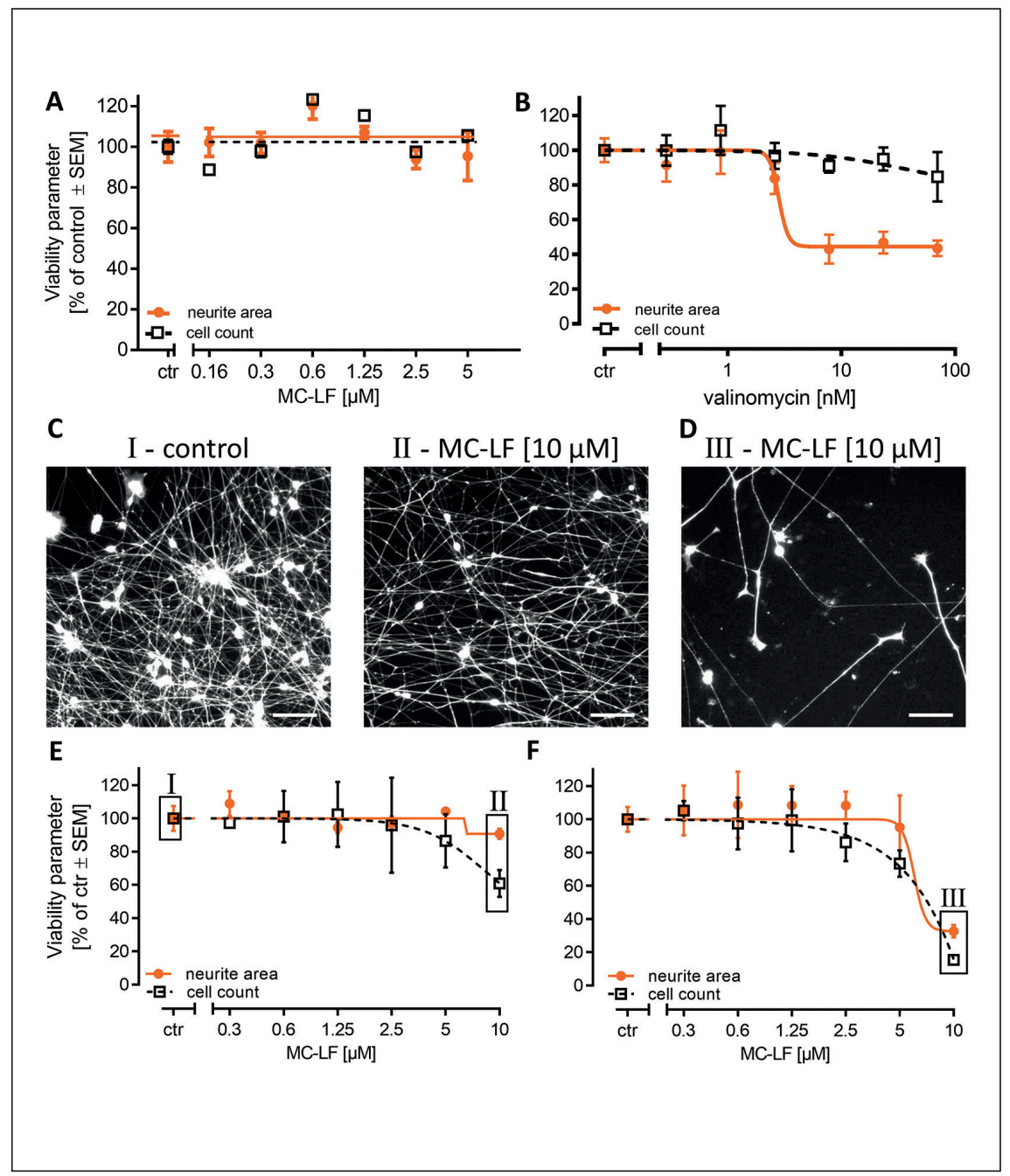

Fig. 3: Effect of MC-LF on peripheral neurons

Peripheral neurons were generated from human pluripotent stem cells according to an established protocol. After thawing, cells were immediately plated on 96-well plates and used for toxicity experiments. (A) Effect of MC-LF on neurite area (orange) and cell count (black) after a $24 \mathrm{~h}$ treatment from DoD0 until DoD1. Data are from three independent experiments, each with three technical replicates.

(B) Effect of the positive control valinomycin on neurite area (orange) and cell count (black) after treatment as in A. Data are from four independent experiments, each with three technical replicates. (C and D) Exemplary pictures of calcein-stained cells treated with solvent (I) or $10 \mu \mathrm{M}$ MC-LF for $48 \mathrm{~h}$ from DoD4 until DoD6 (II) or $10 \mu \mathrm{M} \mathrm{MC}$-LF for $48 \mathrm{~h}$ from DoD4 until DoD6 followed by a 48-h washout period (III). Scale bar is $100 \mu \mathrm{m}$. (E) Effect of MC-LF on neurite area (orange) and cell count (black) after $48 \mathrm{~h}$ treatment from DoD4 until DoD6. Data are means \pm SEM; $\mathrm{N}=3, \mathrm{n}=3(\mathrm{~F})$ Effect of MC-LF on neurite area (orange) and cell count (black) after $48 \mathrm{~h}$ treatment (from DoD4 until DoD6) followed by a 48-h washout period. Data are means $\pm S E M ; N=3, n=3$.

(2014) (Fig. 2D). Over 50\% of the key biological processes of the downregulated oGOs can be assigned to genes involved in development and differentiation. The data of transcriptional changes after $48 \mathrm{~h}$ treatment with MC-LF point to an altered differentiation state of LUHMES, a typical generalized stress response in adult tissues (Desprez et al., 2019).

\subsection{Toxicity of MC-LF on peripheral human neurons}

We used human pluripotent stem cell-derived peripheral neurons as a second neuronal test system (Fig. S3 $\mathrm{A}^{2}$ ). The cells can be generated in large batches and thawed as required for testing (Fig. S3B ${ }^{2}$ ). They provide a suitable test system for mechanistic studies (Hoelting et al., 2016) and screening approaches (Delp et al., 2018). At DoD7 after thawing, the cells express the transporter OATP1A2, which is known to transport MCs (Fig. S3C ${ }^{2}$ ). As peripheral neurons are not protected by the blood-brain barrier, they could be more susceptible to neurotoxicants than neurons of the central nervous system. We used the PeriTox assay, in which more than 100 substances already have been tested (Hoelting et al., 2016; Delp et al., 2018), to investigate the effect of MC-LF on neurite outgrowth in peripheral neurons (Fig. 3A). As positive controls, valinomycin (Fig. 3B), a cyclic peptide with L-amino acids produced by Streptomyces, cisplatin, a chemotherapeutic drug, and tubacin, an HDAC inhibitor (Fig. S3D ${ }^{2}$ ), were used. Tubacin, a specific HDAC6 inhibitor, catalyzes $\alpha$-tubulin acetylation (Gao et al., 2007) and thereby interferes with neurite outgrowth. Peripheral neuropathy, a common side effect of chemotherapeutic drugs, can be mimicked by cisplatin application.

As no changes in viability or neurite area were observed after a $24 \mathrm{~h}$ MC-LF treatment, we also investigated the effects after a longer treatment period. After $48 \mathrm{~h} \mathrm{MC}$-LF treatment with $10 \mu \mathrm{M}$, a reduction in cell count was observed (Fig. 3C). This was even more pronounced after $48 \mathrm{~h}$ of treatment followed by $48 \mathrm{~h}$ of washout (Fig. 3D-F). Under these conditions, not only was the cell count reduced but the neurites were completely broken down (Fig. 3F). In another approach, we tested whether $24 \mathrm{~h}$ treatment at later time points, namely DoD4-5, is also sufficient to see a reduction in cell count or neurite area. Even at concentrations up to $5 \mu \mathrm{M}$ MC-LF, we did not observe a reduction in either of the two parameters (Fig. S3E $E^{2}$ ). We considered acute signaling effects 
as measurable by intracellular calcium changes as an alternative toxicity indicator (Fig. S4A ${ }^{2}$ ). As positive controls, we used cell depolarization by an increase of potassium ions $(30 \mathrm{mM})$ (Fig. $\mathrm{S}_{4} \mathrm{~B}^{2}$ ) in the medium and exposure to ciguatoxin (15 nM) (Fig. $\mathrm{S} 4 \mathrm{C}^{2}$ ), a polyether marine biotoxin specifically inhibiting voltage-gated $\mathrm{Na}^{+}$channels (Daneshian et al., 2013). In both cases, clear increases of intracellular free calcium were observed, while MC-LF $(2.5 \mu \mathrm{M})$ had no effect (Fig. S4A $\left.{ }^{2}\right)$.

\section{Conclusions}

Both in vitro systems used in this study clearly showed that low $\mu \mathrm{M}$ concentrations of MC may lead to human neurotoxicity. Since one of the assays was representative of the peripheral nervous system, which is not protected by the blood-brain barrier, the concentration range identified here would with high likelihood trigger acute human neurotoxicity and may be used as point-of-departure for risk assessment of acute exposure settings. In standard nutritional exposure scenarios (including contaminated drinking water or food), human plasma concentrations are likely to be at least 100 to 1000 -fold below this hazard threshold. It must be noted that this risk assessment statement does not account for parenteral exposure. It also does not allow conclusions on lower level exposures occurring over considerably longer times than tested here. A follow-up study on this would require cultures that can be exposed for several weeks and may use some of the regulated genes that were identified here as biomarkers of subtle effects.

\section{References}

Altaner, S., Puddick, J., Fessard, V. et al. (2019). Simultaneous detection of 14 microcystin congeners from tissue samples using UPLC-ESI-MS/MS and two different deuterated synthetic microcystins as internal standards. Toxins 11, 388. doi:10. 3390/toxins 11070388

Altaner, S., Jaeger, S., Fotler, R. et al. (2020). Machine learning prediction of cyanobacterial toxin (microcystin) toxicodynamics in humans. ALTEX 37, 24-36. doi:10.14573/altex.1904031

Azevedo, S. M. F. O., Carmichael, W. W., Jochimsen, E. M. et al. (2002). Human intoxication by microcystins during renal dialysis treatment in caruaru-brazil. Toxicology 181-182, 441-446. doi:10.1016/s0300-483x(02)00491-2

Botes, D. P., Tuinman, A. A., Wessels, P. L. et al. (1984). The structure of cyanoginosin-LA, a cyclic heptapeptide toxin from the cyanobacterium Microcystis aeruginos. J Chem Soc Perkin Trans 1, 2311-2318.

Bronger, H., König, J., Kopplow, K. et al. (2005). ABCC drug efflux pumps and organic anion uptake transporters in human gliomas and the blood-tumor barrier. Cancer Res 65, 1141911428. doi:10.1158/0008-5472.CAN-05-1271

Buratti, F. M., Manganelli, M., Vichi, S. et al. (2017). Cyanotoxins: Producing organisms, occurrence, toxicity, mechanism of action and human health toxicological risk evaluation. Arch Toxicol 91, 1049-1130. doi:10.1007/s00204-016-1913-6
Carmichael, W. W. (1992). Cyanobacteria secondary metabolites - The cyanotoxins. J Appl Bacteriol 72, 445-459. doi:10. 1111/j.1365-2672.1992.tb01858.x

Chen, J., Xie, P., Li, L. et al. (2009). First identification of the hepatotoxic microcystins in the serum of a chronically exposed human population together with indication of hepatocellular damage. Toxicol Sci 108, 81-89. doi:10.1093/toxsci/ kfp009

Chen, L. and Xie, P. (2016). Mechanisms of microcystin-induced cytotoxicity and apoptosis. Mini Rev Med Chem 16, 10181031. doi:10.2174/1389557516666160219130407

Daneshian, M., Botana, L. M., Dechraoui Bottein, M.-Y. et al. (2013). A roadmap for hazard monitoring and risk assessment of marine biotoxins on the basis of chemical and biological test systems. ALTEX 30, 487-545. doi:10.14573/altex.2013.4.487

Delp, J., Gutbier, S., Klima, S. et al. (2018). A high-throughput approach to identify specific neurotoxicants/ developmental toxicants in human neuronal cell function assays. ALTEX 35, 235-253. doi:10.14573/altex.1712182

Delp, J., Funke, M., Rudolf, F. et al. (2019). Development of a neurotoxicity assay that is tuned to detect mitochondrial toxicants. Arch Toxicol 93, 1585-1608. doi:10.1007/s00204-01902473-y

Desprez, B., Birk, B., Blaauboer, B. et al. (2019). A mode-of-action ontology model for safety evaluation of chemicals: Outcome of a series of workshops on repeated dose toxicity. Toxicol In Vitro 59, 44-50. doi:10.1016/j.tiv.2019.04.005

Devos, D., Moreau, C., Devedjian, J. C. et al. (2014). Targeting chelatable iron as a therapeutic modality in Parkinson's disease. Antioxid Redox Signal 21, 195-210. doi:10.1089/ars. 2013.5593

Dietrich, D. and Hoeger, S. (2005). Guidance values for microcystins in water and cyanobacterial supplement products (blue-green algal supplements): A reasonable or misguided approach? Toxicol Appl Pharmacol 203, 273-289. doi:10.1016/j. taap.2004.09.005

Feurstein, D., Holst, K., Fischer, A. et al. (2009). OATP-associated uptake and toxicity of microcystins in primary murine whole brain cells. Toxicol Appl Pharmacol 234, 247-255. doi:10.1016/j.taap.2008.10.011

Feurstein, D., Stemmer, K., Kleinteich, J. et al. (2011). Microcystin congener- and concentration-dependent induction of murine neuron apoptosis and neurite degeneration. Toxicol Sci 124, 424-431. doi:10.1093/toxsci/kfr243

Fischer, W. J. and Dietrich, D. R. (2000). Pathological and biochemical characterization of microcystin-induced hepatopancreas and kidney damage in carp (Cyprinus carpio). Toxicol Appl Pharmacol 164, 73-81. doi:10.1006/taap.1999.8861

Fischer, W. J., Altheimer, S., Cattori, V. et al. (2005). Organic anion transporting polypeptides expressed in liver and brain mediate uptake of microcystin. Toxicol Appl Pharmacol 203, 257263. doi:10.1016/j.taap.2004.08.012

Gao, Y.-s., Hubbert, C. C., Lu, J. et al. (2007). Histone deacetylase 6 regulates growth factor-induced actin remodeling and endocytosis. Mol Cell Biol 27, 8637-8647. doi:10.1128/MCB. 00393-07 
Gutbier, S., Spreng, A.-S., Delp, J. et al. (2018). Prevention of neuronal apoptosis by astrocytes through thiol-mediated stress response modulation and accelerated recovery from proteotoxic stress. Cell Death Differ 25, 2101-2117. doi:10.1038/ s41418-018-0229-x

Hagenbuch, B. and Meier, P. J. (2003). The superfamily of organic anion transporting polypeptides. Biochim Biophys Acta 1609, 1-18. doi:10.1016/s0005-2736(02)00633-8

Herrera, N., Herrera, C., Ortíz, I. et al. (2018). Genotoxicity and cytotoxicity of three microcystin-LR containing cyanobacterial samples from Antioquia, Colombia. Toxicon 154, 50-59. doi:10.1016/j.toxicon.2018.09.011

Heussner, A. H., Mazija, L., Fastner, J. et al. (2012). Toxin content and cytotoxicity of algal dietary supplements. Toxicol Appl Pharmacol 265, 263-271. doi:doi:10.1016/j.taap.2012.10.005

Hinojosa, M. G., Gutiérrez-Praena, D., Prieto, A. I. et al. (2019). Neurotoxicity induced by microcystins and cylindrospermopsin: A review. Sci Total Environ 668, 547-565. doi:10.1016/j. scitotenv.2019.02.426

Hoelting, L., Klima, S., Karreman, C. et al. (2016). Stem cell-derived immature human dorsal root ganglia neurons to identify peripheral neurotoxicants. Stem Cells Transl Med 5, 476-487. doi:10.5966/sctm.2015-0108

Höllerhage, M., Moebius, C., Melms, J. et al. (2017). Protective efficacy of phosphodiesterase-1 inhibition against alphasynuclein toxicity revealed by compound screening in LUHMES cells. Sci Rep 7, 11469-11469. doi:10.1038/s41598017-11664-5

House, J. S., Grimm, F. A., Jima, D. D. et al. (2017). A pipeline for high-throughput concentration response modeling of gene expression for toxicogenomics. Front Genet 8, 168. doi:10.3389/fgene.2017.00168

$\mathrm{Hu}$, Y., Chen, J., Fan, H. et al. (2016). A review of neurotoxicity of microcystins. Environ Sci Pollut Res Int 23, 7211-7219. doi:10.1007/s11356-016-6073-y

Jochimsen, E. M., Carmichael, W. W., An, J. S. et al. (1998). Liver failure and death after exposure to microcystins at a hemodialysis center in Brazil. N Engl J Med 338, 873-878. doi: 10.1056/NEJM199803263381304

Karreman, C., Klima, S., Holzer, A. K. et al. (2020). CaFFEE: A program for evaluating time courses of $\mathrm{Ca}^{2+}$ dependent signal changes of complex cells loaded with fluorescent indicator dyes. ALTEX 37, 332-336. doi:10.14573/altex.2003191

Krug, A. K., Balmer, N. V., Matt, F. et al. (2013). Evaluation of a human neurite growth assay as specific screen for developmental neurotoxicants. Arch Toxicol 87, 2215-2231. doi:10.1007/ s00204-013-1072-y

Li, Y., Chen, J.-a., Zhao, Q. et al. (2011). A cross-sectional investigation of chronic exposure to microcystin in relationship to childhood liver damage in the Three Gorges Reservoir Region, China. Environ Health Perspect 119, 1483-1488. doi:10.1289/ ehp. 1002412

Livak, K. J. and Schmittgen, T. D. (2001). Analysis of relative gene expression data using real-time quantitative PCR and the $2^{-\Delta \Delta C(T)}$ method. Methods 25, 402-408. doi:10.1006/meth. 2001.1262
Lohren, H., Blagojevic, L., Fitkau, R. et al. (2015). Toxicity of organic and inorganic mercury species in differentiated human neurons and human astrocytes. J Trace Elem Med Biol 32, 200-208. doi:10.1016/j.jtemb.2015.06.008

Lotharius, J., Falsig, J., van Beek, J. et al. (2005). Progressive degeneration of human mesencephalic neuron-derived cells triggered by dopamine-dependent oxidative stress is dependent on the mixed-lineage kinase pathway. J Neurosci 25, 6329-6342. doi:10.1523/JNEUROSCI.1746-05.2005

Love, M. I., Huber, W. and Anders, S. (2014). Moderated estimation of fold change and dispersion for RNA-seq data with DESeq2. Genome Biol 15, 550. doi:10.1186/s13059-014-0550-8

MacKintosh, C., Beattie, K. A., Klumpp, S. et al. (1990). Cyanobacterial microcystin-LR is a potent and specific inhibitor of protein phosphatases 1 and 2A from both mammals and higher plants. FEBS Lett 264, 187-192. doi:10.1016/0014-5793 (90)80245-e

Matelski, L., Morgan, R. K., Grodzki, A. C. et al. (2020). Effects of cytokines on nuclear factor-kappa B, cell viability, and synaptic connectivity in a human neuronal cell line. Mol Psychiatry. doi:10.1038/s41380-020-0647-2

Metsalu, T. and Vilo, J. (2015). Clustvis: A web tool for visualizing clustering of multivariate data using principal component analysis and heatmap. Nucleic Acids Res 43, W566-W570. doi: 10.1093/nar/gkv468

Nishiwaki-Matsushima, R., Ohta, T., Nishiwaki, S. et al. (1992). Liver tumor promotion by the cyanobacterial cyclic peptide toxin microcystin-LR. J Cancer Res Clin Oncol 118, 420-424. doi:10.1007/bf01629424

Pouria, S., de Andrade, A., Barbosa, J. et al. (1998). Fatal microcystin intoxication in haemodialysis unit in Caruaru, Brazil. Lancet 352, 21-26. doi:10.1016/s0140-6736(97)12285-1

Raudvere, U., Kolberg, L., Kuzmin, I. et al. (2019). g:Profiler: A web server for functional enrichment analysis and conversions of gene lists (2019 update). Nucleic Acids Res 47, W191-W198. doi:10.1093/nar/gkz369

Scholz, D., Pöltl, D., Genewsky, A. et al. (2011). Rapid, complete and large-scale generation of post-mitotic neurons from the human luhmes cell line. J Neurochem 119, 957-971. doi:10.1111/j.1471-4159.2011.07255.x

Scholz, D., Chernyshova, Y., Ückert, A.-K. et al. (2018). Reduced $A \beta$ secretion by human neurons under conditions of strongly increased BACE activity. J Neurochem 147, 256-274. doi:10.1111/jnc. 14467

Singh, N., Lawana, V., Luo, J. et al. (2018). Organophosphate pesticide chlorpyrifos impairs STAT1 signaling to induce dopaminergic neurotoxicity: Implications for mitochondria mediated oxidative stress signaling events. Neurobiol Dis 117, 82-113. doi:10.1016/j.nbd.2018.05.019

Skirzewski, M., Karavanova, I., Shamir, A. et al. (2018). ErbB4 signaling in dopaminergic axonal projections increases extracellular dopamine levels and regulates spatial/working memory behaviors. Mol Psychiatry 23, 2227-2237. doi:10.1038/ mp.2017.132

Spoof, L. and Catherine, A. (2016). Appendix 3: Tables of microcystins and nodularins. In J. Meriluoto, L. Spoof and G. 
A. Codd (eds.), Handbook of Cyanobacterial Monitoring and Cyanotoxin Analysis (526-537). John Wiley \& Sons, Ltd. doi:10.1002/9781119068761.app3

Stiegler, N. V., Krug, A. K., Matt, F. et al. (2011). Assessment of chemical-induced impairment of human neurite outgrowth by multiparametric live cell imaging in high-density cultures. Toxicol Sci 121, 73-87. doi:10.1093/toxsci/kfr034

Svirčev, Z., Lalić, D., Bojadžija Savić, G. et al. (2019). Global geographical and historical overview of cyanotoxin distribution and cyanobacterial poisonings. Arch Toxicol 93, 24292481. doi:10.1007/s00204-019-02524-4

Tong, Z.-B., Huang, R., Wang, Y. et al. (2018). The Toxmatrix: Chemo-genomic profiling identifies interactions that reveal mechanisms of toxicity. Chem Res Toxicol 31, 127-136. doi:10.1021/acs.chemrestox.7b00290

Valério, E., Vasconcelos, V. and Campos, A. (2016). New insights on the mode of action of microcystins in animal cells A review. Mini Rev Med Chem 16, 1032-1041. doi:10.2174/13 89557516666160219130553

Waldmann, T., Rempel, E., Balmer, N. V. et al. (2014). Design principles of concentration-dependent transcriptome deviations in drug-exposed differentiating stem cells. Chem Res Toxicol 27, 408-420. doi:10.1021/tx400402j

Weng, M. K., Zimmer, B., Pöltl, D. et al. (2012). Extensive transcriptional regulation of chromatin modifiers during human neurodevelopment. PLoS One 7, e36708-e36708. doi:10.1371/ journal.pone. 0036708
Weng, M. K., Natarajan, K., Scholz, D. et al. (2014). Lineage-specific regulation of epigenetic modifier genes in human liver and brain. PLoS One 9, e102035-e102035. doi:10.1371/ journal.pone.0102035

Witt, B., Meyer, S., Ebert, F. et al. (2017). Toxicity of two classes of arsenolipids and their water-soluble metabolites in human differentiated neurons. Arch Toxicol 91, 3121-3134. doi:10.1007/s00204-017-1933-x

Yoshizawa, S., Matsushima, R., Watanabe, M. F. et al. (1990). Inhibition of protein phosphatases by microcystins and nodularin associated with hepatotoxicity. J Cancer Res Clin Oncol 116, 609-614. doi:10.1007/bf01637082

\section{Conflict of interest}

The authors declare no conflict of interest.

\section{Acknowledgments}

This work was supported by the BMBF, INVITE, EFSA, the DK-EPA (MST-667-00205), and the University of Konstanz. It has received funding from the European Union's Horizon 2020 research and innovation programme under grant agreements No. 681002 (EU-ToxRisk) and No. 825759 (ENDpoiNTs), as well as from CHARM (BadenWürttemberg Wassernetzwerk). We are grateful to Viola Singer and Heidrun Leisner for excellent experimental support. 